\title{
Wheat yield prediction in relation to climatic parameters using statistical model for Ludhiana district of central Punjab
}

\author{
MAHESH CHAND SINGH ${ }^{1 *}$, VAJINDER PAL ${ }^{2}$, SOMPAL SINGH ${ }^{3}$ and SANJAY SATPUTE ${ }^{1}$ \\ ${ }^{1}$ Department of Soil and Water Engineering, ${ }^{2}$ Department of Agronomy and ${ }^{3}$ Department of Climate Change and \\ Agricultural Meteorology, Punjab Agricultural University, Ludhiana, Punjab, India, 141004.
}

Corresponding author: msrawat@pau.edu

\begin{abstract}
Climate change which is one of the main determinants of agricultural production has started affecting the crop growth pattern and yield from past couple of decades in various agro-climatic zones globally. Under such scenario, the prior forecasting of yield of field crops such as wheat via modeling techniques can help in simplifying the crop production management system starting from farmer's level to policy makers. The present study was thus undertaken to model the wheat yield of Ludhiana district of Indian Punjab through regression analysis of historical data (1993-2017) of wheat yield and climatic conditions in the area. The developed model was successfully validated with a strong positive correlation $\left(R^{2}=0.81\right)$ between predicted and observed data. Both observed and predicted yields were having similar trend with a minimum and maximum absolute differential error of 0.1 and $13.9 \%$ respectively. The developed model may serve as a powerful tool for predicting the future yield of wheat crop with available futuristic climatic data of the study area.
\end{abstract}

Keywords: Statistical model, climate, wheat, regression analysis

Wheat (Triticum aestivum L.) is the second major cereal crop of India (Ranjan et al., 2012), contributing about $35.5 \%$ to the total food grain production of the country. However, the climate change which is one of the main determinants of agricultural production has started affecting the pattern of crop growth from last couple of decades throughout the world (Alexandrov and Gerrit 2001). The increasing temperature and exposure to elevated levels of carbon dioxide have negatively affected (directly or indirectly) both crop production and quality. According to Minaxi et al. (2011), the expected rise in average surface temperature may be in the range of $1.1^{\circ} \mathrm{C}-6.4^{\circ} \mathrm{C}$ by the last decade of $21^{\text {st }}$ century on global basis. The average decadal maximum and minimum temperature of Ludhiana district of Indian Punjab is expected to rise by $12.8 \%$ and $29.1 \%$ respectively by the end of $21^{\text {st }}$ century with respect to year 2011 (Singh, 2016). Thus, any change in climatic factors such as temperature and rainfall is bound to have a significant impact on crop growth and production. In the countries like India, the problems would further aggravate in the years to come due to heavy dependence on agriculture if no corrective measures are taken today (Mendelsohn et al., 2006).

As per record, among the major wheat producing districts, Ludhiana alone contributes about $12 \%$ of the total wheat produced in Punjab state (Gill et al., 2018). However, under the present scenario of climate change, the yield of field crops such as wheat crop is significantly being affected by climatic variables such as rainfall, temperature, relative humidity, solar radiation and sunshine hours. Thus, for having improved understanding of the integrated effect of all climatic variables on wheat yield, mathematical models may play a great role. A relationship between crop yield and climatic parameters for quantitative prediction of crop yield can be formed using different techniques one of which is multiple regressions (Bazgeer et al., 2007; Gill et al., 2015). Regression modeling is a simple and straight forward technique, relating the yield with at least one climatic parameter. The main advantages of these models are their limited reliance on field calibration data and transparent assessment of model uncertainties (Lobell and Burke, 2010). Moreover, the models based on climatic parameters can make reliable prediction of crop yield prior to harvest. Besides, precise forecast of crop (wheat) yield can help in simplifying the crop production management system starting from farmer's level to policy makers (at district, state and national levels).

While relating yield data with meteorological parameters using the phenological periods, Shankar and 
Gupta (1988) reported a significant correlation between crop yield and the climatic parameters. Even if, multiple regression models have been developed in past for forecasting yields of different field crops in India such as wheat (Appa Rao, 1983; Gill et al., 2018) and rice (Srinevasan and Banerjee, 1973; Chowdhury et al., 1981), there arises a need to develop new models under the changing climatic patterns and technology trend. Gill et al. 2015 have developed regression models for predicting wheat yield for Central Indian Punjab, however, either the data (yield and climate) used in modelling is quite old, which require update now under changing climate scenario or they have considered only few growth stages of wheat crop while modelling. On the other hand, most recently, Gill et al. (2018) have used the CERES model for predicting wheat yield, which is a case of application of existing model. In contrast, we proposed to develop a new model for predicting wheat yield for Ludhiana district on Indian Punjab using current climatic data as input with more number of growth stages (8-10) of wheat crop for getting better effect of climate change scenario. Thus, the present study was undertaken to develop a model for predicting future wheat yield of Ludhiana district in relation to the climatological parameters affecting it.

\section{MATERIALS AND METHODS}

\section{Description of study site}

Ludhiana district of Punjab State is situated at $30^{\circ} 54^{\prime}$ $\mathrm{N}$ latitude and $75^{\circ} 56^{\prime} \mathrm{E}$ longitude with an average altitude of $247 \mathrm{~m}$ above mean sea level. The area is characterized by semi-arid, sub-tropical climate with very hot summer during April-June and cold winters during December-January. The mean maximum and minimum temperatures show fluctuations during different parts of the year. The summer temperature exceeds $38^{\circ} \mathrm{C}$ and touches $47^{\circ} \mathrm{C}$ with dry summer spells. Winter experiences frost during December and January with minimum temperature below $4^{\circ} \mathrm{C}$. This region is dominated by North Eastern winds during winter season. The average annual rainfall in Ludhiana is $759 \mathrm{~mm}, 75-80 \%$ of which is received during the period from June to September. During winter, rains are scanty and only few showers of cyclonic rains are received by western disturbances. The daily weather data of the past 24 years (1993-2016) of temperature (maximum/minimum), relativehumidity (maximum/minimum), bright sunshine hours and rainfall were collected from Meteorological observatory, Punjab Agricultural University, Ludhiana. The wheat yield data was obtained from the
Statistical Abstracts of Punjab for the above mentioned period of 24 years. The agronomic practices are followed by majority of the farmers in the state of Punjab as recommended in the package of practices annually published by Punjab Agricultural University Ludhiana. The crop growth period was divided into 8 phases with their respective duration (days) from sowing to maturity period (Table 1).

\section{Parameters of modeling}

The model for predicting wheat yield was developed in relation to the prevailing climatic conditions of the study area, recorded during the crop growth period. The parameters or factors of modelling included yield as dependent parameter and climatic data as the independent parameters.

\section{Climatic conditions for study period (1993-2016)}

$\mathrm{T}_{\text {min_BT-HD }}$ was in the range of $4.1-10.6^{\circ} \mathrm{C}$ with minimum and maximum values in year 2007 and 2006 respectively. $\mathrm{T}_{\text {min_HD-ANTH }}$ was in the range of $4.3-12.3^{\circ} \mathrm{C}$ with being minimum and maximum in year 2007 and 2005 respectively. $\mathrm{T}_{\text {max _SW-CRI }}$ was in the range of $22.1-27.0^{\circ} \mathrm{C}$ with minimum and maximum values in year 1997 and 2016 respectively. $\mathrm{RH}_{\text {min_CRI-TL }}$ was in the range of $23.6-30.3 \%$ with minimum and maximum values in year 2014 and 2002 respectively. $\mathrm{RH}_{\text {min_CRI-TL }}$ was in the range of $39.2-76.3 \%$ with minimum and maximum values in year 1993 and 2003 respectively. $\mathrm{RH}_{\text {min_HD-ANTH }}$ was in the range of 37.5-75.0\% with minimum and maximum values in year 2007 and 2006 respectively. $\mathrm{RH}_{\text {max } \_ \text {CRI-TL }}$ was in the range of $91.8-99.6 \%$ with minimum and maximum values in year 2012 and 1999 respectively. $\mathrm{RH}_{\text {max } \_ \text {ВT-HD }}$ was in the range of $91.6-98.2^{\circ} \mathrm{C}$ with minimum and maximum values in year 1993 and 2012 respectively. BSS $_{\text {SW-CRI }}$ was in the range of 116.3-238.6 hours with minimum and maximum values in year 2007 and 1996 respectively. BSS ${ }_{\text {Вт-нD }}$ was in the range of 35.1-112.7 hours with minimum and maximum values in year 2013 and 2000 respectively.

\section{Model development}

A statistical model for predicting yield of wheat crop was developed in XLSTAT software using the climatological parameters viz. temperature $\left(\mathrm{T}_{\min }\right.$ and $\left.\mathrm{T}_{\text {max }}\right)$, relative humidity $\left(\mathrm{RH}_{\min }\right.$ and $\left.\mathrm{RH}_{\max }\right)$ and bright sunshine hours (BSS) as model input. The model was developed using the climatic data for duration of 18 years from 1993 to 2010 and validated by predicting the yield for next 6 years (2011-2016) in relation to available climatic data for that period. Data Analysis (ToolPak) in XLSTAT was used for analysis of the assembled climatic and yield data. Descriptive statistics was studied 
Table 1: Crop growth stages and their respective duration

\begin{tabular}{lll}
\hline Sr. No. & Crop growth stage/phase & Duration (days) \\
\hline I & Sowing (SW) to Crown Root Initiation (CRI) & 26 \\
II & CRI to Tillering (TL) & 30 \\
III & TL to Booting (BT) & 25 \\
IV & BT to Heading (HD) & 11 \\
V & HD to Anthesis (ANTH) & 10 \\
VI & ANTH to Milking (ML) & 13 \\
VII & ML to Dough stage (D) & 16 \\
VIII & D to Maturity (M) & 13 \\
\hline
\end{tabular}

using XLSTAT.

Mathematically, the developed model is given as:

$\mathrm{Y}=21104.5-20.4 \times \mathrm{X}_{1}+5.9 \times \mathrm{X}_{2}+168.5 \times \mathrm{X}_{3}-88.4 \times \mathrm{X}_{4}+27 \times \mathrm{X}_{5}-$ $10.3 \times \mathrm{X}_{6}-53.2 \times \mathrm{X}_{7}-133 \times \mathrm{X}_{8}-4.4 \times \mathrm{X}_{9}-7.3 \times \mathrm{X}_{10}$

Where,

$\mathrm{Y}=$ Yield $\left(\mathrm{kg} \mathrm{ha}^{-1}\right)$

$\mathrm{X}_{1}=\mathrm{T}_{\text {min_BT-HD }}=\operatorname{Min}$. temp. from BT to $\mathrm{HD}\left({ }^{\circ} \mathrm{C}\right)$

$\mathrm{X}_{2}=\mathrm{T}_{\text {min_HD-ANTH }}=$ Min. temp. from $\mathrm{HD}$ to ANTH $\left({ }^{\circ} \mathrm{C}\right)$

$\mathrm{X}_{3}=\mathrm{T}_{\text {max } \_ \text {SW-CRI }}=$ Max. temp. from SW to CRI $\left({ }^{\circ} \mathrm{C}\right)$

$\mathrm{X}_{4}=\mathrm{T}_{\text {max_MI-D }}=$ Max. temp. from MI to $\mathrm{D}\left({ }^{\circ} \mathrm{C}\right)$

$\mathrm{X}_{5}=\mathrm{RH}_{\text {min_CRI-TL }}=$ Min. RH from CRI to TL (\%)

$\mathrm{X}_{6}=\mathrm{RH}_{\text {min_HD-ANTH }}=$ Min. RH from HD to ANTH (\%)

$\mathrm{X}_{7}=\mathrm{RH}_{\text {max } \_ \text {CRI-TL }}=$ Max. $\mathrm{RH}$ from CRI to TL $(\%)$

$\mathrm{X}_{8}=\mathrm{RH}_{\text {max } \_ \text {BT-HD }}=$ Max. $\mathrm{RH}$ from BT to HD (\%)

$\mathrm{X}_{9}=\mathrm{BSS}_{\text {SW-CRI }}=$ Bright sunshine hours from SW to CRI (hours)

$\mathrm{X}_{10}=\mathrm{BSS}_{\mathrm{B \textrm {T }}-\mathrm{HD}}=$ Bright sunshine hours from BT to HD (hours)

\section{Statistical analysis}

The statistical parameters viz. coefficient of determination $\left(\mathrm{R}^{2}\right)$, root mean square error (RMSE), standard error and model efficiency $\left(n_{\text {eff }}\right)$ were computed to test the performance of the developed model. (Nash and Sutcliffe, 1970)

$$
\eta_{e f f}=\left\{1-\frac{\sum_{i=1}^{n}\left(P_{i}-O_{i}\right)^{2}}{\sum_{i=1}^{n}\left(O_{i}-\overline{O_{i}}\right)^{2}}\right\} \times 100
$$

\section{RESULTS AND DISCUSSION}

The observed yield was recorded to be in the range of 4191.0-5373.5 $\mathrm{kg} \mathrm{ha}^{-1}$ with lowest and highest values in year 1995 and 2011 respectively. On the other hand, the predicted yield was estimated to be in the range of 4142.6$5636.4 \mathrm{~kg} \mathrm{ha}^{-1}$ with lowest and highest values in year 1995 and 2016 respectively. During model development, the average observed and predicted yields of wheat yield were 4663.4 and $4664.5 \mathrm{~kg} \mathrm{ha}^{-1}$ respectively. However, during validation, the average observed and predicted yields were 4946.0 and $5165.2 \mathrm{~kg} \mathrm{ha}^{-1}$ respectively. The absolute error was estimated to be in the range of $0.1-5.5 \%$ during model development with an average value of $2.1 \%$. However, during model validation, the absolute error was estimated to be in the range of $0.5-13.9 \%$ with an average value of $7.7 \%$.

\section{Model validation}

The developed model was successfully validated through a strong positive correlation $\left(\mathrm{R}^{2}=0.81\right)$ with the climatic data resulting in a standard error value of $198.3 \mathrm{~kg}$ $\mathrm{ha}^{-1}$. Both, observed and predicted yields were having same trend with a minimum and maximum absolute differential error 0.1 and $13.9 \%$ in year 1999 and 2015 respectively (Fig. 1). The model efficiency $\left(n_{\text {eff }}\right)$ and root mean square error (RMSE) were computed to be $81.9 \%$ and $123.6 \mathrm{~kg} \mathrm{ha}$ ${ }^{1}$ respectively. The yield data in both cases (predicted and observed) were quite close to each other with a linear relation between them, however the predicted data overestimated during years 2014, 2015 and 2016. The minimum difference indicated the close relationship between observed and predicted data. However, the maximum difference indicated an abrupt change in wheat yield under the effect of climatic variables or inputs or the method of cultivation or their combination. Among climatic parameters, $\mathrm{T}_{\text {min_HD-ANTH }}$ had the significant effect on crop development 


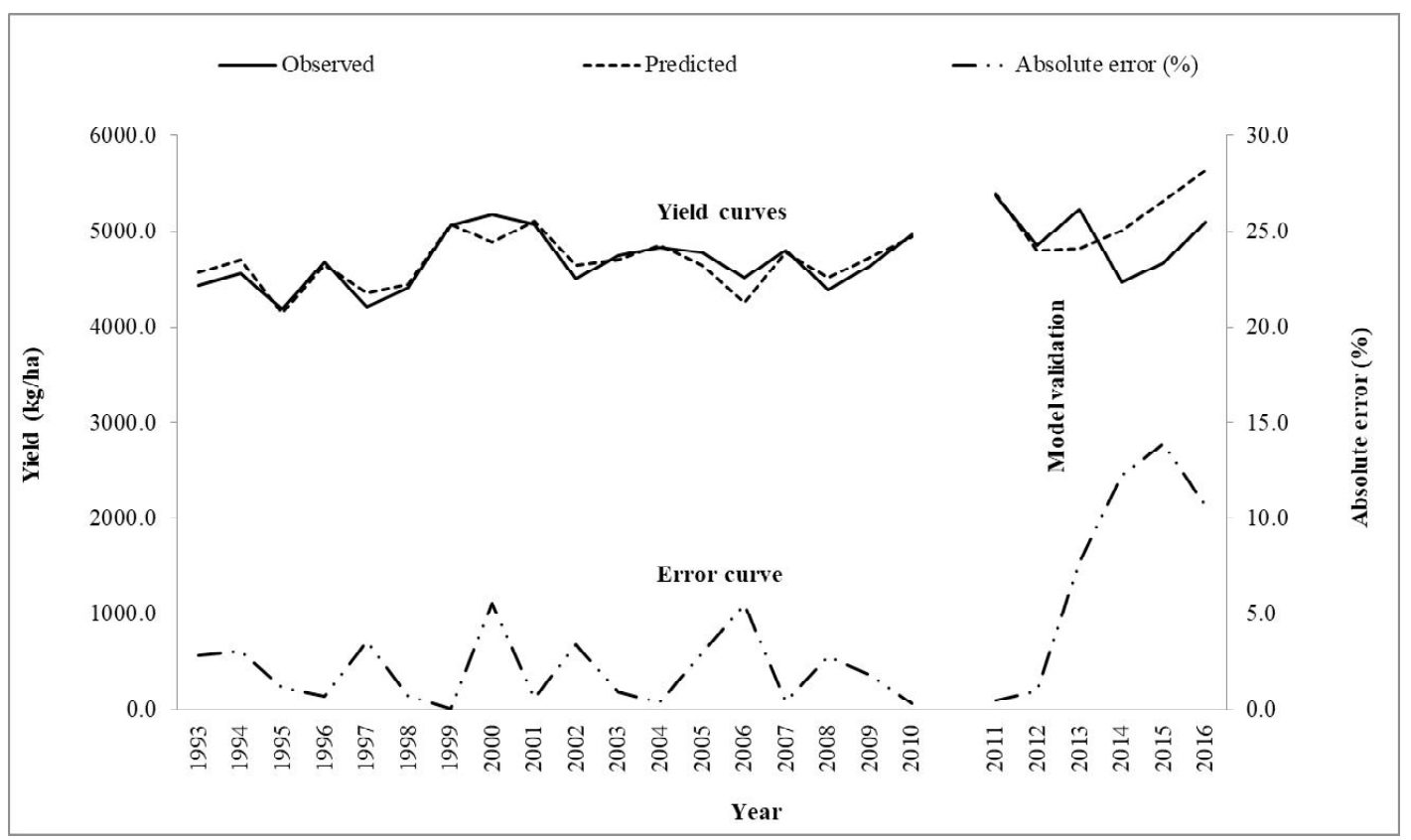

Fig. 1: Simulation of wheat yield (1993-2016)

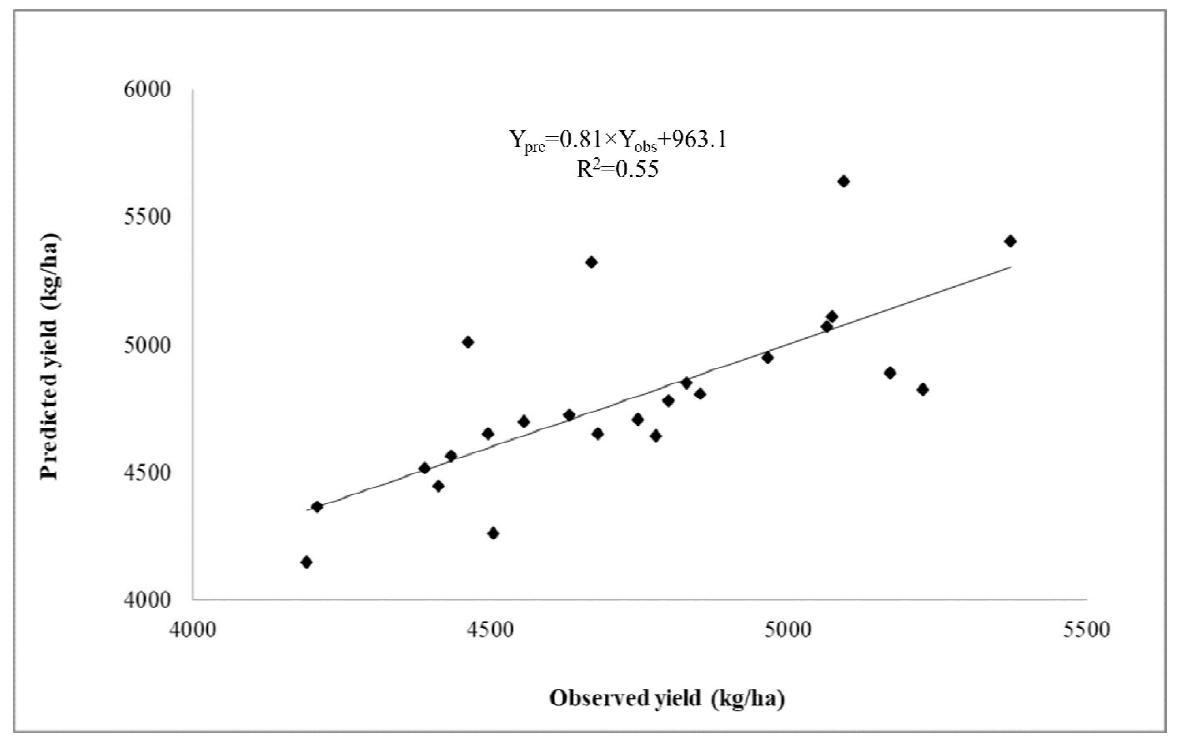

Fig. 2: Relationship between predicted and observed yield data

followed by $\mathrm{T}_{\text {min_BT-HD }}$ On the other hand, $\mathrm{T}_{\text {max _SW-CRI }}$ and $\mathrm{RH}_{\text {min CRI-TL }}$ had the least effect on crop development with having P-value of 0.02 in each case. A linear relationship existed between predicted $\left(\mathrm{Y}_{\text {pre }}\right)$ and observed $\left(\mathrm{Y}_{\mathrm{obs}}\right)$ wheat yield data $\left(\mathrm{R}^{2}=0.55\right)$ as shown in Fig. 2.

$$
\mathrm{Y}_{\mathrm{pre}}=0.81 \times \mathrm{Y}_{\mathrm{obs}}+963.1
$$

\section{CONCLUSION}

The statistical comparison indicated a similar trend between observed and predicted wheat yields with a minimum and maximum absolute differential error of 0.1 (1999) and
$13.9 \%$ (2015) respectively. The developed model has a capability to perform as a powerful tool to forecast the future yield of wheat crop with available climatic data of the study area. It may also help in simplifying the crop production management system starting from farmer's level to policy makers (at district, state and national levels).

\section{REFERENCES}

Alexandrov, V.A. and Gerrit, H. (2001). Climate variation and crop production in Georgia, USA, during the twentieth century. Clim. Res., 17: 33-43. 
Appa Rao, G.J. (1983). Estimation of wheat yields over Punjab using district and state models. Mausam, 34 (3): 275 280 .

Bazgeer, S., Kamali, Gh. and Mortazavi,A. (2007). Wheat yield prediction through agrometeorological indices for Hamedan, Iran. Biaban, 12: 33-38.

Chowdhury, A. and Sarkar, M.B. (1981). Estimation of rice yield through weather factors in a dry sub-humid region. Mausam, 32(4): 393-396.

Gill, K.K., Sandhu, S.S., Kaur, P., Babuta, R. and Bhatt, K. (2015). Wheat yield prediction using weather based statistical model in Central Punjab. J.Agric. Phy., 15(2): 319-321.

Gill, K.K., Sandhu, S.S., Divya and Mishra, S.K. (2018). Preharvest wheat yield prediction using CERES-wheat model for Ludhiana district,weather based statistical model in Central Punjab, India. J. Agrometeorol., 19(4): 319-321.

Lobell, D.B. and Burke, M.B. (2010). On the use of statistical models to predict crop yield responses to climate change. Agric. Forest Meteorol., 150(11): 1443-1452.
Mendelsohn, R., Dinar, A. and Williams, L. (2006). The distributional impact of climate change on rich and poor countries. Environ. Dev. Econ., 11:159-178.

Minaxi, R.P., Acharya, K.O. and Nawale, S. (2011). Impact of climate change on food security. Int. J. Agric. Environ. Biotechnol., 4: 125-127.

Ranjan, R., Nain,A.S. and Panwar, R. (2012). Predicting yield of wheat with remote sensing and weather data. $J$. Agrometeorol., 14: 390-392.

Shankar, U. and Gupta, B.R.D. (1988) Forecasting paddy yield in Bihar and Orissa states in India based on weather parameters and multiple regression technique. Tropical Agric., 65 (3): 265.

Singh, M.C. (2016). Possible futuristic rainfall and temperature variability trend in central Indian Punjab. Res. Environ. Life Sci., 9:100-104.

Srinevasan, P.S. and Banerjee, J.R. (1973). Influence of rainfall on yield of rainfed rice at Kajrat (Colaba District). Agric. Meteorol., 11: 285-292. 